\title{
Longitudinal Analysis of a Very Short Measure of Positive Youth Development
}

Geldhof, G John ; Bowers, Edmond P ; Mueller, Megan Kiely ; Napolitano, Christopher M ; Callina, Kristina Schmid ; Lerner, Richard M

\begin{abstract}
As developmental scientists cease to perceive adolescence as a period of inevitable turmoil and adopt the Positive Youth Development (PYD) perspective, psychometrically sound measurement tools will be needed to assess adolescents' positive attributes. In this article we examine the longitudinal stability of the very short version of the PYD scale developed as part of the 4-H Study of PYD. Using a sample of 7,071 adolescents (60\% female) followed between Grades 5 and 12, our results suggest general stability of PYD across adolescence, both in terms of mean levels and rank-order stability. We also show that both a global measure of PYD and the individual Five Cs of PYD consistently correlate with important criterion measures (i.e., contribution, depressive symptoms, and problem behaviors) in expected ways. Although our results suggest weak relationships among our three criteria, we especially note that across adolescence PYD becomes more strongly correlated with contribution but less strongly correlated with depressive symptoms, and that confidence becomes more strongly related to depressive symptoms. We discuss implications for use of the present PYD measure in youth development programs.
\end{abstract}

DOI: https://doi.org/10.1007/s10964-014-0093-Z

Posted at the Zurich Open Repository and Archive, University of Zurich

ZORA URL: https://doi.org/10.5167/uzh-108445

Journal Article

Accepted Version

Originally published at:

Geldhof, G John; Bowers, Edmond P; Mueller, Megan Kiely; Napolitano, Christopher M; Callina, Kristina Schmid; Lerner, Richard M (2014). Longitudinal Analysis of a Very Short Measure of Positive Youth Development. Journal of Youth and Adolescence, 43(6):933-949.

DOI: https://doi.org/10.1007/s10964-014-0093-z 
THE FIVE CS MODEL OF POSITIVE YOUTH DEVELOPMENT SHORT FORM: A LONGITUDINAL ANALYSIS OF THE CONFIRMATORY FACTOR STRUCTURE AND MEASUREMENT INVARIANCE

G. John Geldhof

Oregon State University

Edmond P. Bowers

Tufts University

Megan Kiely Mueller

Tufts University Cummings School of Veterinary Medicine

Christopher M. Napolitano

University of Zurich

Kristina Schmid Callina

Richard M. Lerner

Tufts University

Author Note

This research was supported by a grant from the Thrive Foundation for Youth.

Correspondence should be addressed to G. John Geldhof, College of Public Health and Human Sciences,470 Waldo Hall, Corvallis, OR 97331. E-mail: John.Geldhof@oregonstate.edu. 


\begin{abstract}
As developmental scientists cease to perceive adolescence as a period of turmoil and adopt the Positive Youth Development (PYD) perspective, psychometrically sound measurement tools will be needed to assess adolescents' positive attributes. In this paper we examine the longitudinal stability of the very short version of the PYD scale developed as part of the 4-H Study of Positive Youth Development. Using a sample of more than 7,000 adolescents followed between Grades 5 and 12, our results suggest general stability of PYD across adolescence, both in terms of mean levels and rank-order stability. We additionally show that a global measure of PYD consistently correlates with important criterion measures (i.e., Contribution, Depression, and Risk/Problem Behaviors) in expected ways, while the variance in each $\mathrm{C}$ that is not related to global PYD relates to these criteria in differential and changing ways during adolescence.
\end{abstract}

Keywords: positive youth development, short form, confirmatory factor analysis (CFA), longitudinal measurement invariance, adolescence 


\section{Longitudinal Analysis of a Very \\ Short Measure of PYD}

Research on adolescent development is often framed by a "deficit perspective" that describes the second decade of life as a period of "storm and stress" (Hall, 1904), developmental disturbance (Freud, 1969), or crisis (Erikson, 1968). This perspective treats adolescents as problems to be managed (Roth \& Brooks-Gunn, 2003b), with positive development during this period of life indexed as the absence of, or decreases in, problem behaviors. The pervasive influence of the deficit perspective on research aims, policy, and practice is reflected in the prevalence of measures of risk and problem behaviors used by program and service organizations to assess youth functioning. Looking at the field of youth development in the early years of this century, it appeared that it is easier to determine what youth should avoid (e.g., violence, drugs mental health problems) than to identify youth characteristics and experiences that are indicators of thriving, positive development, or well-being (Moore, Lippman, \& Brown, 2004).

Partly in response to this focus on the problems and deficits among young people, a new approach to adolescent development has emerged over the past two decades - the positive youth development (PYD) perspective (J. Lerner, Phelps, Forman, \& Bowers, 2009; J. Lerner, Bowers et al., 2013; Lerner, Lerner et al., 2011). The PYD perspective moves beyond a deficit-centered view of youth, and instead emphasizes that all youth have personal strengths that can be developed in ways that that optimize positive functioning.

Several theoretical frameworks now approach development from the PYD perspective (for a review, see J. Lerner, Bowers et al., 2013), and as these models become more popular it is important that they are empirically valid, can be widely applied, and include constructs that are 
specific and measurable. However, these models are just beginning to be tested. Recent work has attempted to evaluate youth development frameworks (Heck \& Subramaniam, 2009) and indicators of PYD (Dukakis, London, McLaughlin, \& Williamson, 2009), but further investigation of suitable models is needed. In this paper we discuss one popular model of PYD, the Lerner and Lerner $5 \mathrm{Cs}$ Model, and extend findings that support its empirical validity across adolescence.

\section{The Five Cs Model of PYD}

The purpose of this paper is to provide information about a questionnaire developed to assess PYD based on the Lerner and Lerner Five Cs Model of PYD (Bowers et al., 2010; Jeličić Bobek, Phelps, Lerner, \& Lerner, 2007; Lerner et al., 2005; Phelps et al., 2009). This model operationalizes positive development through the assessment of five "Cs" - Competence, Confidence, Character, Connection, and Caring - found to be important for youth development according to the experiences of practitioners and based on extensive reviews of the adolescent development literature (Eccles \& Gootman, 2002; Lerner, 2004; Roth \& Brooks-Gunn, 2003a, b). We present definitions of these Cs in Table 1, but note that all Five Cs are fully integrated such that PYD requires healthy development in all five domains (see also Dukakis et al., 2009).

The Five Cs were linked to the positive outcomes of youth development programs reported by Roth and Brooks-Gunn (2003a, b). In addition, these "Cs" are prominent terms used by practitioners, adolescents involved in youth development programs, and the parents of these adolescents in describing the characteristics of a "thriving youth" (King et al., 2005). In turn, when young people manifest these Five Cs over the course of adolescence, they are more likely to be on a life trajectory marked by mutually-beneficial person $\leftrightarrow$ context relations that contribute to self, family, community, and civil society (i.e., contribution - the sixth C - 
emerges; Lerner, 2004). The young person is also less likely to be on a trajectory of risk and problem behaviors, such as substance abuse, delinquency, and depression. That is, as evidence for positive behavior increases, the PYD perspective hypothesizes that there will be fewer indications of problematic behaviors (e.g., Benson, Mannes, Pittman, \& Ferber, 2004; Pittman,

Irby, \& Ferber, 2001). Although recent research supports a general inverse relation between PYD and risk/problem behaviors, these findings also indicate that a more complex pattern of positive and negative developmental trajectories; these pathways are not simply inversely related (LewinBizan et al., 2010; Phelps et al., 2007). Nevertheless, PYD is associated across development with positive indicators such as contribution, school engagement, successful intentional selfregulation, and hope.

\section{Structure and Validity of PYD as an Aggregate Score}

The 4-H Study of Positive Youth Development (e.g., Lerner et al., 2005) is a longitudinal study spanning from Grade 5 to, at this writing, Grade 12, and has provided the primary empirical support for the Five Cs Model. Using data from the first wave (Grade 5) of the study, Lerner et al. (2005) proposed and tested a higher-order measure of PYD that consisted of five first-order latent constructs, each representing one of the Cs. In a subsequent study, structural equation models were constructed to test the validity of the Five Cs model (Jeličić et al., 2007). Results suggested that the Five Cs can be cast in terms of latent constructs, which in turn load on a higher-order PYD latent construct. This structure suggests that the Five Cs can be summarized by a single indicator of positive development. This PYD construct significantly predicted criterion indices of positive functioning measured one year later, including community contributions, depression, and an aggregate measure of delinquency and substance use (Jeličić et al., 2007). 
More recently, Phelps et al. (2009) and Bowers et al. (2010) extended the above findings by assessing the structure and development of PYD from Grade 5 to Grade 7, and from Grade 8 through 10 of the 4-H Study, respectively. While the fitted models required a large number of residual covariances among indicators, the results of these studies supported previous findings and indicated that the higher-order structure of PYD continued to be robust across adolescence. The global measure of PYD also displayed high stability across adolescence, especially between Grades 5 and 7 (i.e., stability correlations of approximately .88), although the scales relevant to measuring the Five Cs were slightly different for two of the Cs during middle adolescence than in early adolescence. That is, reflective of developmental change, athletic competence was no longer a relevant indicator of competence during middle adolescence; however, physical appearance significantly loaded on the latent construct of confidence.

A series of dual-trajectory analyses presented by Lewin-Bizan and colleagues (2010) similarly extended Jeličić and colleagues' (2007) findings that suggest relations between a global measure of PYD (taken as the average of all Five Cs of PYD) and important criterion variables. Using latent class growth analysis, Lewin-Bizan and colleagues (2010) estimated growth trajectories for PYD, Risk Behaviors, and Depressive Symptoms using data from Grades 5 through 10 of the 4-H Study of PYD. By cross-tabulating trajectory membership, their findings suggested that participants on more optimal trajectories of PYD tended to be on more optimal trajectories of both criteria. That is, these results suggest longitudinally stable negative relations between PYD as indexed by the Five Cs model and indicators of negative development.

\section{A Bifactor Model of the Five Cs of PYD}

Despite robust evidence supporting the validity of an aggregate/higher-order measure of PYD, recent evidence suggests that the individual Cs may provide a more nuanced picture of 
PYD than that provided by a global measure of PYD. For instance, Geldhof and colleagues (in press) describe a bifactor model of PYD in which all indicators of PYD load onto two constructs: a global measure that aggregates across all Cs and one of five specific constructs that represent the variance in each $\mathrm{C}$ after controlling for global PYD (see Figure 1). In such a bifactor model the global PYD construct provides a rough, heuristic estimate of each adolescent's positive functioning that aggregates across all PYD indicators. The residual C constructs then represent the covariance among the items within each $\mathrm{C}$ that is not related to global PYD.

The bifactor model of PYD has both empirical and theoretical advantages over the previously implemented higher-order model. Empirically, the bifactor model provides statistically better fit to the 4-H data than does a higher-order model (see Geldhof et al., in press). Theoretically, a bifactor model also maps more directly onto the 5 Cs model of PYD discussed by Lerner, Lerner, and their colleagues (e.g., Lerner et al., 2005). A higher-order model of PYD necessarily assumes that each participant has a set (albeit latent) level of PYD that causes their level of each $\mathrm{C}$. These latent $\mathrm{C}$ scores then cause individuals to score in certain ways on each indicator in the model. A bifactor model instead treats global PYD as one of multiple sources of item true score variance. Because PYD cuts across items this global measure is akin to the variance of group means in multilevel modeling. In addition, the bifactor model allows indicators to systematically covary with each other in ways related to each unique $C$, thus suggesting that each item has two sources of true-score variance. Accordingly, a bifactor model also allows both the global PYD scale AND the residual C constructs to independently covary with important criterion measures (e.g., contribution, depression).

In the present paper we extend previous research by examining the bifactor structure of PYD as indexed by the Five Cs of PYD across all eight waves of the 4-H study. We test the 
measure's structure and factorial invariance across all eight waves, while also presenting findings that speak directly to the stability and criterion validity of the overarching measure of PYD as well as for the residual C constructs that represent systematic item variance not directly related to the overarching PYD measure. Specifically, we examine the mean-level and correlational stability for all PYD constructs as well as examining the correlations between these constructs and the criterion variables of Contribution, Depression, and Risk/Problem Behaviors across eight years of adolescence.

\section{Method}

Full details of the 4-H Study of Positive Youth Development have been presented elsewhere (Lerner et al., 2005, 2009, 2010, 2011). Therefore, we present here only the features of the methods relevant to the present research, which includes data from all eight waves. A complete discussion of the procedure and overall sample is provided in the introductory chapter of this volume (Bowers, Geldhof, Johnson, Lerner, \& Lerner, this volume).

\section{Participants}

We analyzed data from 7071 adolescents who participated in the 4-H Study. As Table 2 shows, the mean age of participants was $10.94(S D=.42)$ in the Grade 5 assessment and 17.71 $(S D=.76)$ in Grade 12 . With respect to race/ethnicity, the sample was $65.8 \%$ White; $7.6 \%$ Black; 9.4\% Latino; and 14.4\% other (including Asian, Native American, Multiethnic/multiracial, or "other"). Participants resided in diverse communities, with 35.7\% living in rural areas; $16.3 \%$ in urban areas; and $25.7 \%$ in suburban areas $(22.2 \%$ had missing data for locale). Our sample's demographic characteristics were not completely stable across all waves of the study, however, with female and Caucasian participants over-represented in later waves of the data. 
In addition, participants' parents provided data regarding the socioeconomic status of their families. In Grade 5, 20\% of mothers attended or completed high school; $24.8 \%$ completed some college; and $18.6 \%$ had a bachelor's degree or higher (35.8\% did not respond); average per capita income at Grade 5 was about $\$ 13,657(S D=\$ 8,348)$, and ranged to $\$ 23,401(S D=$ $\$ 13,798$ ) in Grade 12 (also see Table 2).

\section{Measures}

Positive Youth Development. We operationalized PYD using the very short measure of the Five Cs of PYD discussed by Geldhof and colleagues (in press). The Five Cs model identifies PYD consisting of the Five Cs discussed in Table 1. Our measure of PYD drew items from several primary sources, including: the Search Institute's Profiles of Student Life-Attitudes and Behaviors (PSL-AB) scale (Benson, Leffert, Scales, \& Blyth, 1998; Leffert et al., 1998); the Self-Perception Profile for Children (Harter, 1983); the Self-Perception Profile for Adolescents (Harter, 1986, 1988); Teen Assessment Project (TAP) Survey Question Bank (Small, \& Rodgers, 1995); Eisenberg Sympathy Scale (Eisenberg et al., 1996); and the Empathic Concern Subscale of the Interpersonal Reactivity Index (IRI; Davis, 1980). At Grades 5 through 7, we used the Self-Perception Profile for Children (Harter, 1983). Beginning at Grade 8 and continuing through Grade 12, we used the Self-Perception Profile for Adolescents (Harter, 1986, 1988; we used the 1986 version for Grade 8 and the 1988 version for Grades 9 to 12).While previous research has suggested that the structure of PYD changes across adolescence (e.g., Bowers et al., 2010), we included all scales used to measure PYD in any wave of the 4-H study in our analyses to maintain longitudinal consistency.

As discussed by Geldhof and colleagues (in press), the PYD-VSF measures Competence using three items, one item representing Academic Competence, Social Competence, and 
Physical Competence, respectively. All Competence items asked participants to select the type of person they were more like between two choices (e.g., "Some teenagers do very well at their class work, BUT Other teenagers don't do very well at their class work.") and then to decide if it was "really true" or "sort of true" for him/her. The PYD-VSF similarly measures Confidence using three items, one representing Self Worth, Positive Identity, and Physical Appearance, respectively. The Self-Worth and Physical Appearance items followed the same response format (e.g.," Some teenagers are happy with themselves most of the time, BUT Other teenagers are often not happy with themselves"), while the Positive Identity item was scored using a five-point Likert-type scale (e.g., "All in all, I a m glad to be me").

The measure of Character in the PYD-VSF includes four items, with one representing Social Conscience, Values Diversity, Conduct Behavior, and Personal Values, with all items except the one indicating Conduct Behavior scored on a five-point Likert-type scale (e.g., "Helping to make the world a better place to live in"). The Conduct Behavior item follows a similar response format to the Competence items above ("Some teenagers do things they know they shouldn't do, BUT Other teenagers hardly ever do things they know they shouldn't do"). Items representing Caring and Connection items were all scaled on a five-point Likert-type scale, with Caring represented by three items representing empathic responding (e.g., "When I see someone being picked on, I feel sorry for them"), and the Connection scale containing four items that represent connection to participants' families, neighborhoods, schools, and peers, respectively (e.g., "I have lots of good conversations with my parents," and "Adults in my town or city make me feel important").

Criteria. To ensure that the factor structure of PYD remained stable (i.e., did not change) in the presence of important outcomes, single-item composites for the following scales were 
included in all confirmatory factor analyses ${ }^{1}$. Outcome measures were included for each wave of data and, while not a primary focus of this research, the substantive relationships between PYD and these outcomes are considered in the results below.

Contribution. At each grade of the 4-H Study, participants responded to twelve items which were weighted and summed to create a composite measure of contribution. These items were derived from existing instruments with known psychometric properties and used in largescale studies of adolescents, including the Search Institute's Profiles of Student Life-Attitudes and Behaviors (PSL-AB) scale (Benson et al.,1998; Leffert et al., 1998) and the Teen Assessment Project (TAP) Survey Question Bank (Small \& Rodgers, 1995).

Contribution was comprised of two equally weighted subscales - ideology and actions and each subscale included 6 items. The ideology subscale measured the extent to which contribution was an important facet of youth's identity and future self. An example ideology subscale item stated, "It is important to me to contribute to my community and society" with response options ranging from $1=$ strongly disagree to $5=$ strongly agree. An example item that assessed one's future ideological orientation gauged the perceived chances that the young person would be involved in community service in the future, with a response format that ranged from 1 $=$ very low to $5=$ very high. The action subscale of contribution was comprised of three components: helping, leadership, and service. Items from the helping, leadership, and service components measured the frequency of time youth spent helping others (i.e., friends and neighbors), acting in leadership roles (i.e., being a leader in a group or organization within the last 12 months), and providing service to their communities (i.e., volunteering, mentoring/peer advising, and participating in school government), respectively. The composite contribution

\footnotetext{
${ }^{1}$ Single-item composites were chosen to ensure that model fit was not negatively impacted by minor misspecification of the factor structure of the outcome scales.
} 
scores ranged from 0 to 100, with higher scores indicating higher levels of contribution. For the current study sample, the Cronbach's alphas for the contribution scale were .40 at Grade 5 and .68 at Grade 6; however, the alphas ranged from .75 to .81 across Grades 7 through 12.

Depression. We measured depressive symptomatology using the 20 -item, self-report Center for Epidemiological Studies Depression scale (CES-D; Radloff, 1977). This scale conceptualizes depressive symptomatology by several components: "depressed mood, feelings of guilt and worthlessness, feelings of helplessness and hopelessness, psychomotor retardation, loss of appetite, and sleep disturbance" (Radloff, 1977, p. 386). Respondents indicated how often they experienced particular symptoms during the past week. Example items included: "I was bothered by things that usually don't bother me" and "I felt sad." Four items were positively worded and included: "I felt hopeful about the future" and "I enjoyed life." The response options ranged from $0=$ rarely or none of the time (less than 1 day) to $3=$ most or all of the time (5-7 days). Items were summed for a total score, with a maximum value of 60 , and higher scores were indicative of higher depressive symptomatology (i.e., greater frequency and number of symptoms of depression). Cronbach's alphas for the CES-D scale ranged from 0.81 to 0.89 across Grades 5 through 12 in the present study.

Risk behaviors. We assessed indicators of substance use and delinquency derived from items included in the Search Institute's Profiles of Student Life-Attitudes and Behaviors (PSLAB) scale (Leffert et al., 1998) and the Monitoring the Future (2000) questionnaire to indicate adolescent risk behaviors.

Substance use. At Grade 5, five items assessed the frequency of substance use during the past 12 months. Specifically, we asked students whether or not they had ever smoked cigarettes; used chewing tobacco or snuff; had any beer, wine, wine coolers, or liquor to drink - more than 
just a few sips; used marijuana (grass, pot) or hashish (hash, hash oil); and used any other drug, such as ecstasy, speed, LSD, heroin, crack or cocaine. In addition to the previously mentioned items, students in Grades 6 through 12 indicated whether they had ever sniffed glues, sprays or gases. We then added a final item asking whether respondents had ever taken steroid pills or shots without a doctor's prescription in Grades 7 through 12. The response options for all substance use items ranged from $0=$ never to $3=$ regularly.

Delinquency. We assessed Grade 5 delinquency using four items that indicated the frequency of delinquent behavior during the past 12 months. Specifically, we asked students how many times they had stolen something from a store; gotten into trouble with the police; hit or beat up someone; and damaged property just for fun (such as breaking windows, scratching a car, putting graffiti on walls, etc.). At Grade 7 and continuing through Grade 12, an additional item assessed how many times the student carried a weapon (such as a gun, knife, club, etc.). The response format for the delinquency items ranged from $0=$ never to $4=$ five or more times.

For consistency, the delinquency items were rescaled so that their values ranged from 0 to 3. The averages for the substance use and delinquency items, respectively, were calculated and transformed to range from 0 to 15 . A composite measure was then calculated by summing the averages of both subscales for a maximum score of 30, with higher scores indicating higher levels of risk behaviors. For the current study sample, the Cronbach's alphas for the risk behaviors scale were .65 at Grade 5 and .71 at Grade 6; the alphas ranged from 0.76 to 0.86 across Grades 7 through 12.

\section{Analyses}

We implemented a series of overlapping longitudinal CFA models that established the factorial invariance of the PYD-VSF across all waves of the 4-H study. As suggested by Geldhof 
and colleagues (2013), we modeled the PYD-VSF using a bifactor model that specified each item as loading onto both an overarching PYD factor, as well as loading onto a factor representing that item's respective C independent of PYD (see Figure 1). These analyses allowed us to examine longitudinal changes in the means, variances, and correlations among both a general measure of PYD, as well as each individual C. Due to the very large model size, we ran four sets of CFA models that considered Grades 5 through 7, Grades 7 through 9, Grades 9 and 10, and Grades 10 through 12, respectively. All analyses implemented FIML estimation which is robust in the presence of missing data when the MAR assumption is met. Mmissing data percentages are summarized in Table 3. Finally, we examined the latent correlations among PYD and each criterion variable.

\section{Results}

\section{Validation of the PYD-VSF}

We established longitudinal invariance for the first model (Grades 5 through 7) using standard procedures, then established invariance for the three later models by fixing parameters in these models to equal the corresponding estimates in the strong invariance model that examined Grades 5 through 7. Establishing invariance across all waves scaled all latent means and variances in a comparable metric and allowed us to then explore developmental trends in the latent parameters across adolescence, despite the fact that different waves were examined in different models.

All initial CFAs for the PYD-VSF displayed acceptable model fit, and we established partial factorial invariance across all waves of data using the change in CFI criterion suggested by Cheung and Rensvold $(2002$; i.e., $\Delta \mathrm{CFI}<.01)$. We present fit for these models in Table 4. The finding of partial invariance indicates that some factor loadings and intercepts changed over 
time and can be interpreted to mean that the item-construct relationships and the expected score of some items when their respective latent construct was zero changed over time. Table 5 presents standardized factor loadings from the strong invariance models, and Table 6 presents raw-metric item intercepts from the same models. As these tables show, a majority of the changes occur in Grade 9, suggesting that the qualitative meaning of the latent constructs changes slightly as adolescents enter high school. Fewer than half of the factor loadings or intercepts changed within any given wave, however, meaning that it is still reasonable to compare latent parameters between any two concurrent waves.

Standardized factor loadings suggested that the general PYD factor was indicated by items from all Five Cs, but was weakly indicated by Social Competence, Physical Competence, and Physical Appearance. The residual Five C constructs were also indicated by nearly all of their respective indicators, although the conduct behavior item did not meaningfully load onto the residual Character construct. In addition, the Connection to Peers item loaded weakly onto the residual Connection construct, suggesting that the residual Connection construct emphasized Connection to Ecological Resources (family, neighborhood, and school).

\section{Stability and Relations Among the PYD Constructs}

Latent means and variances for all constructs are presented in Table 7, while latent correlations from the PYD-VSF strong invariance model are presented in Table 8. Because we established partial invariance across all waves, latent means and variances can be directly compared across time and these parameter estimates can be used to approximate developmental trajectories for each construct across adolescence. The only exception is Character, which seemed to qualitatively change during high school (i.e., three out of four factor loadings and three out of four intercepts were not invariant across the middle waves of data collection). The 
development of the Character construct must therefore be qualified by the fact that the Values Diversity subscale became more important for Character, while the Conduct Behavior (which only weakly indicated character) and Personal Values subscales became less important for Character over time.

Results suggested rank-order and mean-level stability for PYD across time while the residual $\mathrm{C}$ constructs displayed lower levels of stability. The unique $\mathrm{C}$ constructs generally showed moderate rank-order stability during early adolescence that became stronger over time. Character and Caring also displayed general mean-level stability over time, although the remaining $\mathrm{C}$ constructs tended to show mean-level declines over time, especially during the high school years. These results suggest that general adaptive functioning is relatively stable across adolescence while the specific aspects of PYD (i.e., levels of each C, controlling for PYD) display intra-individual variability.

Replicating previous findings from the 4-H Study that treated PYD as a second-order latent construct, our bifactor models suggested strong correlations among several Cs. Competence and Confidence were highly correlated within time, suggesting that participants who rate themselves as being competent also rate themselves as having high self-confidence, even after controlling for interindividual differences in PYD. Character and Caring similarly correlated with each other while displaying consistently low correlations with Competence and Confidence. Connection displayed consistently high correlations with Competence and Confidence and consistently weak correlations with Caring. Connection also displayed moderate to high correlations with Character early in adolescence that decreased in magnitude during later adolescence. Thus, the residual $\mathrm{C}$ constructs tended to aggregate in two groups, efficacious 
(Competence and Competence) and socioemotional (Character and Caring), with Connection correlating positively with each group.

\section{Correlations with Criterion Variables}

Similar to previous research that examined PYD as a higher-order latent construct, our bifactor measure of general PYD displayed consistently significant correlations with all three criterion variables across all eight waves of the 4-H Study. Table 9 presents the latent correlations among PYD, Depression, Risk, and Contribution. Unsurprisingly, PYD correlated negatively with indices of negative development (i.e., Depression and Risk) and correlated positively with our indicator of positive development (i.e., Contribution). The magnitude of the correlations between PYD and both Contribution and Risk increased over time, suggesting that across the 4-H Study, PYD became increasingly related to behavioral indices of positive development. However, the correlation between PYD and Depression attenuated slightly over time, suggesting a weak bifurcation of the constructs across adolescence.

In contrast to the findings for general PYD, the residual $\mathrm{C}$ constructs representing efficacious development (Confidence and Competence) displayed weak to moderate correlations with behavioral measures of positive development (Contribution and Risk) but increasingly strong (negative) correlations with depression. While unsurprising given the tight coupling between depression and having a negative self-image (e.g., Harter \& Jackson, 1993), we must additionally interpret these relations in the context of each residual $\mathrm{C}$ being completely orthogonal to general PYD. Thus, while our general index of PYD slowly decoupled with depression across adolescence, depression became increasingly correlated with participants' efficacious self-concepts. 
While the correlations between our criterion variables and both PYD and the two efficacious Cs displayed a consistent pattern of development, the correlations between our criteria and the residual Cs that represent socioemotional functioning (Character and Caring) displayed greater stability. The socioemotional Cs moderately correlated (positively) with both Contribution and Depression while being generally unrelated with Risk across adolescence. The positive correlations between the socioemotional Cs and Depression are especially surprising, but again must be interpreted in light of the fact that these two Cs both represent socioemotional functioning independent of general PYD. While this finding must be replicated in future work, we can abductively speculate that self-reported Caring and Character that exceeds the levels expected from participants' level of general PYD may indicate emotional hypersensitivity, or an anxiety-producing over concern for (or about) others' thoughts and feelings that correlates with increased depressive symptomology.

The final residual C, Connection, displayed criterion correlations that were somewhat similar to those displayed by the efficacious Cs, yet also somewhat like the sociomoral Cs. That is, Connection displayed moderately positive correlations with Contribution and essentially zero correlations with Risk across adolescence, mirroring the parallel correlations between the sociomoral Cs and those same criterion variables. Similar to the efficacious Cs, Connection also displayed negative correlations with Depression that increased in magnitude over time. Connection was therefore consistently related to Contribution behaviors across adolescence and may buffer against Depression in late adolescence.

\section{Discussion}

Evaluating youth development frameworks and indicators of PYD remain as an important tasks for developmental researchers; while existing evidence supports the empirical validity of 
such models, further empirical investigation is needed. In this paper we discuss one popular model of PYD, the Lerner and Lerner 5 Cs Model, and extend findings that support its empirical validity across adolescence. We extend previous research by examining the bifactor structure of PYD as indexed by the Five Cs of PYD across all eight waves of the 4-H study, establishing factorial invariance across time while also presenting findings that speak directly to the stability and criterion validity of the overarching measure of PYD as well as for the residual C constructs that represent systematic item variance not directly related to the overarching PYD measure.

Our findings suggest moderate rank-order stability of PYD and the residual C constructs during early adolescence, which increases in magnitude to indicate strong rank-order stability by late adolescence. Inter-individually, most constructs displayed mean-level stability although the Competence, Confidence, and Connection constructs displayed mean-level declines over time. The relative mean-level stability of the Character and Caring constructs mirrors their generally stable criterion correlations, while the mean-level changes in Competence, Confidence, and Connection also reflect the longitudinally increasing criterion correlation between those constructs and Depression. Our general measure of PYD displayed stability both in terms of the magnitude of criterion correlations and mean levels across adolescence, however.

The differential development of the PYD and residual C constructs, and especially the differential development of the criterion correlations that each construct displayed offers added support for continued examination of the Five Cs of PYD using a bifactor framework. While not addressed as a target hypothesis in this paper, the factor loadings presented in Table 5 further highlight this point, reinforcing findings presented by Geldhof and colleagues (in press) that found differential relations between specific indicators and the general vs. residual C constructs. For instance, PEER 6, the item measuring connection to peers indicated PYD much more 
strongly than it indicated the residual Connection construct, while other Connection indicators represented the two constructs more equally.

\section{Interpreting Cross-Time Differences}

Given that the present study reports the first-ever examination of PYD and its relations with important criterion variables across all eight waves of the 4-H Study of Positive Youth Development, as well as the first attempt to substantively interpret stability and criterion correlations for a bifactor model of PYD, our findings add potentially important information to the field's understanding of the Five Cs of PYD and their development across adolescence. Our results suggest several marked differences between early and late adolescence while highlighting the joint importance of both global PYD and the individual Cs.

Any developmental differences presented in this study must be interpreted with caution, however, as our longitudinal findings conflate maturational change with a number of nondevelopmental factors. For example, our sample moved from being heterogeneous and generally representative in earlier waves to having disproportionately large numbers of Caucasian, female and higher-SES participants. Future research should therefore replicate these longitudinal findings with a diverse array of independent samples. Similarly, only a fraction of the 4-H Study's more than 7,000 participants provided data in any given wave, with the overlap between adjacent waves often being relatively small. Estimates of rank-order stability assume complete data between adjacent waves of data, at it is not entirely clear how limited overlap between waves affected our stability estimates in this paper. On one hand, we might argue that missingness occurred at random and should have little impact on our stability estimates. It is entirely possible that attrition was not completely random, however, and if this was in fact the case, our stability estimates may be inflated as a result, for instance, of being estimated using 
only data from our most dedicated/consistent participants.

\section{Future Directions}

The present bifactor models add to our understanding of PYD and its relations with important criteria, supplementing previous research that has largely implemented higher-order CFA models and mixture regression analyses. The PYD data from the 4-H Study are far from being fully explored, however, and our findings only represent a single stepping stone in the larger path to understanding the development of positive functioning during adolescence and beyond. Future research must continue to consider not only which factors moderate relations among the Five Cs of PYD and important criteria, but also continue exploring how important predictors of positive development (e.g., self-regulation, see Geldhof, Little, \& Colombo, 2010; McClelland, Ponitz, Messersmith, \& Tominey, 2010) relate to the various facets of PYD when it is modeled with a bifactor structure. Fully understanding these relations will require triangulation across multiple quantitative and qualitative methods, as well as a nuanced understanding of how context moderates the above processes. As such, even though the present results summarize eight years of the 4-H Study of Positive Youth Development, they mark only the beginning steps of an exciting and quickly growing body of literature that focuses on positive development both among youth and across the life span. 


\section{References}

Benson, P. L., Leffert, N., Scales, P. C., \& Blyth, D. A. (1998). Beyond the "village" rhetoric: Creating healthy communities for children and adolescents. Applied Developmental Science, 2(3), 138-159.

Benson, P. L., Mannes, M., Pittman, K., \& Ferber, T. (2004). Youth development, developmental assets, and public policy. In R. M. Lerner, L. Steinberg, R. M. Lerner, L. Steinberg (Eds.), Handbook of adolescent psychology (2nd ed.) (pp. 781-814). Hoboken, NJ US: John Wiley \& Sons Inc.

Bowers, E. P., Li, Y., Kiely, M. K., Brittian, A., Lerner, J. V., \& Lerner, R. M. (2010). The Five Cs model of positive youth development: A longitudinal analysis of confirmatory factor structure and measurement invariance. Journal of Youth and Adolescence, 39, 720-735.

Cheung, G. W., \& Rensvold, R. B. (2002). Evaluating goodness-of-fit indexes for testing measurement invariance. Structural Equation Modeling, 9(2), 233-255.

Davis, M. (1980). A multidimensional approach to individual differences in empathy. Catalog of Selected Documents in Psychology, 10(4), 1-17.

Dukakis, K., London, R. A., McLaughlin, M., \& Williamson, D. (2009). Positive youth development: Individual, setting and system level indicators. (Issue brief: Positive youth development indicators). Stanford, CA: John W. Gardner Center for Youth and Their Communities.

Eccles, J., \& Gootman, J. (Eds). (2002). Community programs to promote youth development. Washington, D.C.: National Academy Press.

Eisenberg, N., Fabes, R. A., Murphy, B. C., Karbon, M., Smith, M., \& Maszk, P. (1996). The relations of children's dispositional empathy-related responding to their emotionality, 
regulation, and social functioning. Developmental Psychology, 32, 195-209.

Erikson, E.H. (1968). Identity: youth and crisis. Oxford, England: Norton \& Co.

Freud, A. (1969). Adolescence as a developmental disturbance. In G. Caplan \& S. Lebovici (Eds.), Adolescence (pp. 5-10). New York: Basic Books.

Geldhof, G. J., Bowers, E. P., Boyd, M. J., Mueller, M. K., Napolitano, C. M., Schmid, K. L., Lerner, J. V., \& Lerner, R. M. (in press). The creation and validation of short and very short measures of PYD. Journal of Research in Adolescence.

Geldhof, G. J., Little, T. D., \& Colombo, J. (2010). Self-regulation across the lifespan. In M. E. Lamb \& A. M. Freund (Vol. Eds.), and R. M. Lerner (Editor-in-Chief). Social and emotional development. Volume 2 of The Handbook of Life-span Development (pp. 116 157). Hoboken, NJ: Wiley.

Hall, G. S. (1904). Adolescence: Its psychology and its relations to physiology, anthropology, sociology, sex, crime, religion, and education (Vols. 1 \& 2). New York: Appleton.

Harter, S. (1983). Supplementary description of the Self-Perception Profile for Children: Revision of the Perceived Competence Scale for Children. Unpublished manuscript, University of Denver.

Harter, S. (1986). Manual for the Self-Perception Profile for Adolescents. Denver, CO: University of Denver.

Harter, S. (1988). Manual for the Self-Perception Profile for Adolescents. Denver, CO: University of Denver.

Harter, S. \& Jackson, B. K. (1993). Young adolescents' perceptions of the link between low selfworth and depressed affect. Journal of Early Adolescence, 13(4), 383-407.

Heck, K. E., \& Subramaniam, A., (2009). Youth development Frameworks. [Monograph]. Davis, CA: 4-H Center for Youth Development, University of California. 
Jeličić, H., Bobek, D., Phelps, E., D., Lerner, J. V., Lerner, R. M. (2007). Using positive youth development to predict contribution and risk behaviors in early adolescence: Findings from the first two waves of the 4-H Study of Positive Youth Development. International Journal of Behavioral Development, 31(3), 263-273.

King, P. E., Dowling, E. M., Mueller, R. A., White, K., Schultz, W., Osborn, P., Dickerson, E., Bobek, D. L., Lerner, R. M., Benson, P. L., \& Scales, P. C. (2005). Thriving in Adolescence: The voices of youth-serving practitioners, parents, and early and late adolescents. Journal of Early Adolescence, 25(1), 94-112.

Leffert, N., Benson, P. L., Scales, P. C., Sharma, A. R., Drake, D. R., \& Blyth, D. A. (1998). Developmental assets: Measurement and prediction of risk behaviors among adolescents. Applied Developmental Science, 2(4), 209-230.

Lerner, J. V., Bowers, E. P., Minor, K., Boyd, M. J., Mueller, M. K., Schmid, K. L., Napolitano, C. M., Lewin-Bizan, S., \& Lerner, R. M. (2013). Positive youth development: Processes, philosophies, and programs. In R. M. Lerner, M. A., Easterbrooks, \& J. Mistry (Eds.), Handbook of Psychology, Volume 6: Developmental Psychology ( $2^{\text {nd }}$ edition). Editor-inchief: I. B. Weiner. Hoboken, NJ: Wiley.

Lerner, J. V., Phelps, E., Forman, Y., \& Bowers, E. P. (2009). Positive youth development. In R. M. Lerner, L. Steinberg, R. M. Lerner, L. Steinberg (Eds.), Handbook of adolescent psychology, Vol 1: Individual bases of adolescent development (3rd ed.) (pp. 524-558). Hoboken, NJ US: John Wiley \& Sons Inc.

Lerner, R. M. (2004). Liberty: Thriving and civic engagement among American youth. Thousand Oaks, CA: Sage. 
Lerner, R. M., Lerner, J. V., Almerigi, J., Theokas, C., Phelps, E., Gestsdottir, S. Naudeau, S., Jeličić, H., Alberts, A. E., Ma, L., Smith, L. M., Bobek, D. L., Richman-Raphael, D., Simpson, I., Christiansen, E. D., \& von Eye, A. (2005). Positive youth development, participation in community youth development programs, and community contributions of fifth grade adolescents: Findings from the first wave of the 4-H Study of Positive Youth Development. Journal of Early Adolescence, 25(1), 17-71.

Lerner, R.M., Lerner, J.V., Bowers, E.P., Lewin-Bizan, S., \& von Eye, A. (Eds.) (2011). Individual and contextual bases of thriving in adolescence: Findings from the 4-H Study of Positive Youth Development. Journal of Adolescence, 34(6).

Lerner, R. M., Lerner, J. V., Lewin-Bizan, S., Bowers, E. P., Boyd, M., Mueller, M., Schmid, K., Napolitano, C. (2011). Positive youth development: Processes, programs, and problematics. Journal of Youth Development, 6(3), 40-64.

Lerner, R. M., von Eye, A., Lerner, J. V., \& Lewin-Bizan, S. (2009). Exploring the foundations and functions of adolescent thriving within the 4-H study of positive youth development: A view of the issues. Journal of Applied Developmental Psychology, 30(5).

Lerner, R.M., von Eye, A., Lerner, J.V., Lewin-Bizan, S., \& Bowers, E.P. (Eds.). (2010). The meaning and measurement of thriving in adolescence: Findings from the 4-H Study of Positive Youth Development. Journal of Youth and Adolescence, 39(7).

Lewin-Bizan, S., Lynch, A. D., Fay, K., Schmid, K., McPherran, C., Lerner, J. V., \& Lerner, R. M. (2010). Trajectories of positive and negative behaviors from early- to middle-adolescence. Journal of Youth and Adolescence, 39(7), 751-763.

McClelland, M. M., Ponitz, C. C., Messersmith, E., \& Tominey, S. (2010). Self-regulation: The integration of cognition and emotion. In R. Lerner (Series Ed.) \& W. Overton (Vol. Ed.), 
Handbook of life-span development. (Vol. 1: Cognition, biology and methods, pp. 509553). Hoboken, NJ: Wiley \& Sons.

Monitoring the Future (2000). National survey on drug use, 1975-2000. Bethesda, MD: National Institute on Drug Abuse.

Moore, K. A., Lippman, L., \& Brown, B. (2004). Indicators of child well-being: The promise for Positive Youth Development. Annals of the American Academy of Political and Social Science. Special Issue: Positive Development: Realizing the Potential of Youth, 591, $125-$ 145.

Phelps, E., Balsano, A., Fay, K., Peltz, J., Zimmerman, S., Lerner, R., M., \& Lerner, J. V. (2007). Nuances in early adolescent development trajectories of positive and of problematic/risk behaviors: Findings from the 4-H Study of Positive Youth Development. Child and Adolescent Clinics of North America, 16(2), 473-496.

Phelps, E., Zimmerman, S., Warren, A. E. A., Jeličič, H., von Eye, A., \& Lerner, R. M. (2009). The structure and developmental course of Positive Youth Development (PYD) in early adolescence: Implications for theory and practice. Journal of Applied Developmental Psychology, 30(5), 571-584.

Pittman, K., Irby, M., \& Ferber, T. (2001). Unfinished business: Further reflections on a decade of promoting youth development. In P. L. Benson \& K. J. Pittman (Eds.), Trends in youth development: Visions, realities and challenges (pp. 4-50). Norwell, MA: Kluwer.

Radloff, L. S. (1977). The CES-D scale: A self-report depression scale for research in the general population. Applied Psychological Measurement, 1(3), 385-401.

Roth, J. L., \& Brooks-Gunn, J. (2003a). What is a youth development program? Identification and defining principles. In. F. Jacobs, D. Wertlieb, \& R. M. Lerner (Eds.), Enhancing the 
life chances of youth and families: Public service systems and public policy perspectives: Vol. 2 Handbook of applied developmental science: Promoting positive child, adolescent, and family development through research, policies, and programs (pp. 197-223). Thousand Oaks, CA: Sage.

Roth, J. L., \& Brooks-Gunn, J. (2003b). What exactly is a youth development program? Answers from research and practice. Applied Developmental Science, 7, 94-111.

Small, S. A., \& Rodgers, K. B. (1995). Teen Assessment Project (TAP) Survey Question Bank. Madison: University of Wisconsin-Madison. 
Table 1

Definitions of the Five Cs of Positive Youth Development

C Definition

Competence Positive view of one's actions in domain specific areas including social, academic, cognitive, and vocational. Social competence pertains to interpersonal skills (e.g., conflict resolution). Cognitive competence pertains to cognitive abilities (e.g., decision making). School grades, attendance, and test scores are part of academic competence. Vocational competence involves work habits and career choice explorations, including entrepreneurship.

Confidence An internal sense of overall positive self-worth and self-efficacy; one's global self-regard, as opposed to domain specific beliefs.

Connection Positive bonds with people and institutions that are reflected in bidirectional exchanges between the individual and peers, family, school, and community in which both parties contribute to the relationship.

Character Respect for societal and cultural rules, possession of standards for correct behaviors, a sense of right and wrong (morality), and integrity.

Caring A sense of sympathy and empathy for others.

Note. Derived from Lerner et al. (2005) and Roth \& Brooks-Gunn (2003a). 
Table 2

Participant demographics in the 4-H Study of PYD, by Grade

\begin{tabular}{|c|c|c|c|c|c|c|c|c|}
\hline & Grade 5 & Grade 6 & Grade 7 & Grade 8 & Grade 9 & Grade 10 & Grade 11 & Grade 12 \\
\hline \multirow[t]{2}{*}{ Age $M(S D)$} & 10.94 & 12.01 & 13.00 & 14.02 & 14.98 & 15.82 & 16.83 & 17.71 \\
\hline & $(0.42)$ & $(0.43)$ & $(0.47)$ & $(0.53)$ & $(0.57)$ & $(0.70)$ & $(0.76)$ & $(0.76)$ \\
\hline \multicolumn{9}{|l|}{ Mother's Education (\%) } \\
\hline High School or Less & 20.8 & 18.2 & 13.2 & 6.4 & 2.8 & 1.2 & 1.0 & 1.6 \\
\hline Some College & 24.8 & 22.1 & 19.4 & 9.9 & 9.1 & 4.2 & 4.3 & 1.4 \\
\hline BA or Higher & 18.6 & 17.8 & 18.2 & 10.3 & 8.5 & 6.8 & 4.4 & 3.2 \\
\hline$\%$ Missing & 35.8 & 42.0 & 49.3 & 73.4 & 79.6 & 87.8 & 90.3 & 93.8 \\
\hline Mean Per Capita Income & 13656.86 & 13635.81 & 16553.42 & 19137.40 & 19981.29 & 24331.31 & 24981.29 & 23401.44 \\
\hline$(S D)$ & $(8348.46)$ & $(8621.05)$ & $(10631.93)$ & $(13216.27)$ & $(12938.41)$ & $(18664.92)$ & $(17316.31)$ & $(13798.49)$ \\
\hline
\end{tabular}


Table 3

Percent missing data for each construct, by Grade

\begin{tabular}{|c|c|c|c|c|c|c|c|c|}
\hline & Grade 5 & Grade 6 & Grade 7 & Grade 8 & Grade 9 & Grade 10 & Grade 11 & Grade 12 \\
\hline Contribution & 39.52 & 21.65 & 6.91 & 5.69 & 10.25 & 5.71 & 10.65 & 5.24 \\
\hline CES-D & 14.99 & 8.38 & 6.65 & 4.50 & 8.63 & 5.16 & 9.66 & 6.83 \\
\hline Risk Behavior & 7.40 & 3.49 & 14.53 & 4.50 & 18.23 & 9.58 & 9.21 & 6.35 \\
\hline \multicolumn{9}{|l|}{ PYD Items } \\
\hline Minimum & 9.03 & 9.43 & 1.10 & 0.95 & 6.69 & 1.22 & 6.40 & 1.43 \\
\hline Maximum & 39.08 & 23.88 & 18.59 & 10.58 & 40.56 & 9.44 & 9.78 & 9.21 \\
\hline Ave. \% Missing & 21.30 & 17.89 & 9.24 & 5.69 & 20.36 & 3.74 & 7.65 & 3.33 \\
\hline
\end{tabular}


Table 4

Model fit for PYD-VSF Models

\begin{tabular}{|c|c|c|c|c|c|c|c|c|c|}
\hline Grades 5,6 , and 7 & $\chi^{2}$ & $\mathrm{df}$ & RMSEA & $\mathrm{CFI}$ & TLI & $\Delta \chi^{2}$ & $\Delta \mathrm{df}$ & $p$ & $\Delta \mathrm{CFI}$ \\
\hline CFA & 1985.02 & 1194 & $.02(.01, .02)$ & 0.96 & 0.94 & & & & \\
\hline Weak Invariance & 2132.95 & 1245 & $.02(.01, .02)$ & 0.95 & 0.94 & 147.93 & 51 & $<0.001$ & -0.005 \\
\hline Strong Invariance & 2187.09 & 1264 & $.02(.01, .02)$ & 0.95 & 0.94 & 54.15 & 19 & $<0.001$ & -0.002 \\
\hline Final & 2215.24 & 1276 & $.02(.01, .02)$ & 0.95 & 0.94 & 28.15 & 12 & 0.005 & -0.001 \\
\hline Grades 7,8 , and 9 & $\chi^{2}$ & $\mathrm{df}$ & RMSEA & $\mathrm{CFI}$ & TLI & $\Delta \chi^{2}$ & $\Delta \mathrm{df}$ & $p$ & $\Delta \mathrm{CFI}$ \\
\hline CFA & 2424.79 & 1311 & $.02(.02, .02)$ & 0.95 & 0.93 & & & & \\
\hline Weak Invariance & 2682.44 & 1401 & $.02(.02, .02)$ & 0.94 & 0.92 & 257.66 & 90 & $<0.001$ & -0.008 \\
\hline Strong Invariance & 2919.64 & 1437 & $.02(.02, .02)$ & 0.93 & 0.91 & 237.20 & 36 & $<0.001$ & -0.009 \\
\hline Final & 2942.74 & 1451 & $.02(.02, .02)$ & 0.93 & 0.91 & 23.09 & 14 & 0.059 & 0.000 \\
\hline Grades 9 and 10 & $\chi^{2}$ & $\mathrm{df}$ & RMSEA & $\mathrm{CFI}$ & TLI & $\Delta \chi^{2}$ & $\Delta \mathrm{df}$ & $p$ & $\Delta \mathrm{CFI}$ \\
\hline CFA & 1115.71 & 562 & $.02(.02, .02)$ & 0.96 & 0.94 & & & & \\
\hline Weak Invariance & 1230.86 & 607 & $.02(.02, .02)$ & 0.95 & 0.93 & 115.15 & 45 & $<0.001$ & -0.006 \\
\hline Strong Invariance & 1327.47 & 626 & $.02(.02, .02)$ & 0.94 & 0.93 & 96.61 & 19 & $<0.001$ & -0.006 \\
\hline Final & 1340.32 & 634 & $.02(.02, .02)$ & 0.94 & 0.93 & 12.84 & 8 & 0.117 & 0.000 \\
\hline Grades 10,11 , and 12 & $\chi^{2}$ & df & RMSEA & CFI & TLI & $\Delta \chi^{2}$ & $\Delta \mathrm{df}$ & $p$ & $\Delta \mathrm{CFI}$ \\
\hline CFA & 2303.42 & 1311 & $.02(.02, .02)$ & 0.95 & 0.92 & & & & \\
\hline Weak Invariance & 2555.19 & 1400 & $.02(.02, .02)$ & 0.94 & 0.92 & 251.77 & 89 & $<0.001$ & -0.009 \\
\hline Strong Invariance & 2750.86 & 1439 & $.02(.02, .02)$ & 0.93 & 0.91 & 195.66 & 39 & $<0.001$ & -0.009 \\
\hline Final & 2778.83 & 1458 & $.02(.02, .02)$ & 0.93 & 0.91 & 27.97 & 19 & 0.084 & 0.000 \\
\hline
\end{tabular}


Table 5

Standardized Factor Loadings from the PYD-VSF Strong Invariance Models*

\begin{tabular}{|c|c|c|c|c|c|c|c|c|}
\hline Grade & 5 & 6 & 7 & 8 & 9 & 10 & 11 & 12 \\
\hline \multicolumn{9}{|l|}{ Competence } \\
\hline HART25 & 0.32 & 0.36 & 0.36 & 0.34 & 0.33 & 0.32 & 0.33 & 0.35 \\
\hline HART08 & 0.45 & 0.48 & 0.48 & 0.48 & 0.45 & $\underline{0.44}$ & 0.44 & 0.46 \\
\hline HART21 & 0.47 & 0.55 & 0.55 & 0.48 & 0.41 & $\overline{0.46}$ & 0.44 & 0.46 \\
\hline \multicolumn{9}{|l|}{ Confidence } \\
\hline HART18 & 0.50 & 0.55 & 0.52 & 0.59 & 0.58 & $\underline{0.55}$ & 0.58 & 0.60 \\
\hline ABME10 & 0.28 & 0.31 & 0.29 & 0.38 & 0.52 & $\overline{0.37}$ & 0.38 & 0.39 \\
\hline HART10 & 0.42 & 0.45 & 0.47 & 0.61 & 0.64 & 0.64 & 0.63 & 0.65 \\
\hline \multicolumn{9}{|l|}{ Character } \\
\hline ABME21 & 0.68 & 0.70 & 0.55 & 0.54 & 0.50 & 0.51 & 0.54 & 0.56 \\
\hline ABME41 & 0.34 & 0.41 & 0.31 & 0.31 & 0.42 & 0.41 & 0.42 & 0.43 \\
\hline HART29 & 0.00 & 0.00 & $\underline{-0.03}$ & 0.00 & $\overline{\mathbf{0 . 1 0}}$ & -0.12 & -0.12 & -0.12 \\
\hline ABME29 & 0.61 & 0.61 & $\overline{0.48}$ & 0.46 & $\overline{0.41}$ & $\underline{0.31}$ & 0.32 & 0.36 \\
\hline \multicolumn{9}{|l|}{ Caring } \\
\hline CARE2 & na & 0.64 & 0.59 & 0.60 & $\underline{0.50}$ & 0.52 & 0.50 & 0.51 \\
\hline CARE7 & na & 0.79 & 0.71 & 0.72 & $\overline{0.77}$ & 0.76 & 0.74 & 0.77 \\
\hline CARE9 & na & 0.79 & 0.72 & 0.72 & 0.76 & 0.76 & 0.74 & 0.74 \\
\hline \multicolumn{9}{|l|}{ Connection } \\
\hline FAM5 & 0.28 & 0.32 & 0.25 & 0.27 & 0.27 & 0.31 & 0.31 & 0.32 \\
\hline NEIGH3 & 0.57 & 0.57 & 0.52 & 0.58 & 0.56 & 0.50 & 0.50 & 0.50 \\
\hline CLAS05 & 0.44 & 0.45 & 0.39 & 0.44 & 0.44 & 0.41 & 0.40 & 0.41 \\
\hline PEER6 & 0.12 & 0.12 & 0.11 & 0.12 & $\underline{0.23}$ & 0.22 & 0.22 & 0.22 \\
\hline \multicolumn{9}{|l|}{ PYD } \\
\hline HART25 & 0.33 & 0.37 & 0.42 & 0.41 & 0.29 & 0.43 & 0.39 & 0.42 \\
\hline HART08 & 0.17 & 0.19 & 0.21 & 0.22 & 0.13 & 0.22 & 0.19 & 0.20 \\
\hline HART21 & 0.02 & 0.02 & 0.02 & 0.02 & 0.02 & 0.02 & 0.02 & 0.02 \\
\hline HART18 & 0.34 & 0.37 & 0.40 & 0.37 & 0.34 & 0.38 & 0.51 & 0.36 \\
\hline ABME10 & 0.43 & 0.48 & 0.52 & 0.55 & $\underline{0.37}$ & $\underline{0.44}$ & 0.41 & 0.42 \\
\hline HART10 & 0.16 & 0.17 & 0.20 & 0.21 & $\overline{0.13}$ & $\overline{0.23}$ & 0.20 & 0.21 \\
\hline ABME21 & 0.36 & 0.37 & 0.43 & 0.45 & 0.46 & 0.47 & 0.43 & 0.45 \\
\hline ABME41 & 0.22 & 0.27 & 0.30 & 0.32 & 0.30 & 0.29 & 0.27 & 0.27 \\
\hline HART29 & 0.38 & 0.44 & 0.49 & 0.46 & 0.61 & 0.49 & 0.43 & 0.45 \\
\hline ABME29 & 0.40 & 0.39 & 0.46 & 0.47 & 0.46 & 0.49 & 0.46 & 0.50 \\
\hline CARE2 & na & 0.30 & 0.36 & 0.38 & 0.39 & 0.40 & 0.40 & 0.41 \\
\hline CARE7 & na & 0.35 & 0.41 & 0.44 & 0.42 & 0.42 & 0.42 & 0.44 \\
\hline CARE9 & na & 0.36 & 0.43 & 0.46 & 0.42 & 0.42 & 0.43 & 0.43 \\
\hline FAM5 & 0.44 & 0.50 & 0.50 & 0.51 & 0.49 & 0.45 & 0.41 & 0.42 \\
\hline NEIGH3 & 0.33 & 0.33 & 0.40 & 0.40 & 0.37 & 0.38 & 0.34 & 0.34 \\
\hline CLAS05 & 0.38 & 0.38 & 0.44 & 0.45 & 0.43 & 0.45 & 0.40 & 0.41 \\
\hline PEER6 & 0.32 & 0.33 & 0.40 & 0.40 & 0.40 & $\underline{0.28}$ & 0.25 & 0.25 \\
\hline
\end{tabular}

Estimates from analyses where target grade is earliest (e.g., Grade 7 comes from the model of Grades 7, 8, and 9)

Bold indicates a temporary change in the raw-metric factor loading

Bold and underlined represents relatively stable changes in the raw-metric factor loading

*Item labels represent the Early Adolescent item labels. See Appendix A for corresponding labels in the middle/late adolescent forms 
Table 6

Raw-Metric Intercepts from the PYD-VSF Strong Invariance Models*

\begin{tabular}{ccccccccc}
\hline Grade & 5 & 6 & 7 & 8 & 9 & 10 & 11 & 12 \\
\hline Competence & & & & & & & & \\
HART25 & 3.20 & 3.20 & 3.20 & 3.20 & 3.20 & $\underline{\mathbf{3 . 3 8}}$ & 3.38 & 3.38 \\
HART08 & 3.32 & 3.32 & 3.32 & 3.32 & 3.32 & 3.32 & 3.32 & 3.32 \\
HART21 & 2.73 & 2.73 & 2.73 & 2.73 & $\mathbf{2 . 5 5}$ & 2.73 & 2.73 & 2.73 \\
Confidence & & & & & & & & \\
HART18 & 3.39 & 3.39 & 3.39 & 3.39 & 3.39 & 3.39 & 3.39 & 3.39 \\
ABME10 & 4.30 & 4.30 & 4.30 & 4.30 & $\underline{\mathbf{4 . 2 4}}$ & $\underline{\mathbf{4 . 3 8}}$ & 4.38 & 4.38 \\
HART10 & 2.96 & 2.96 & 2.96 & 2.96 & 2.96 & 2.96 & 2.96 & 2.96 \\
Character & & & & & & & & \\
ABME21 & 4.03 & 4.03 & 4.03 & 4.03 & 4.03 & 4.03 & 4.03 & 4.03 \\
ABME41 & 3.47 & 3.93 & $\underline{\mathbf{3 . 8 9}}$ & $\underline{\mathbf{3 . 8 5}}$ & 3.85 & 3.85 & 3.85 & 3.85 \\
HART29 & 2.89 & 2.89 & 2.89 & 2.89 & $\underline{\mathbf{2 . 7 3}}$ & 2.73 & 2.73 & 2.73 \\
ABME29 & 4.04 & 4.04 & 4.04 & 4.04 & 4.04 & $\underline{\mathbf{4 . 1 7}}$ & 4.17 & 4.17 \\
Caring & & & & & & & & \\
CARE2 & na & 3.78 & 3.78 & 3.78 & $\underline{\mathbf{3 . 9 5}}$ & 3.95 & 3.95 & 3.95 \\
CARE7 & na & 3.80 & 3.80 & 3.80 & 3.80 & 3.80 & 3.80 & 3.80 \\
CARE9 & na & 3.82 & 3.82 & 3.82 & 3.82 & 3.82 & 3.82 & 3.82 \\
Connection & & & & & & & & \\
FAM5 & 4.31 & 4.31 & 4.31 & 4.31 & 4.31 & 4.31 & 4.31 & 4.31 \\
NEIGH3 & 3.74 & 3.74 & 3.74 & 3.74 & 3.74 & 3.74 & 3.74 & 3.74 \\
CLAS05 & 3.99 & 3.99 & 3.99 & 3.99 & 3.99 & $\underline{\mathbf{4 . 0 9}}$ & 4.09 & 4.09 \\
PEER6 & 4.36 & 4.36 & 4.36 & 4.36 & 4.36 & $\underline{\mathbf{4 . 4 7}}$ & 4.47 & 4.47
\end{tabular}

Estimates from analyses where target grade is earliest (e.g., Grade 7 comes from the model of Grades 7, 8, and 9)

Bold indicates a temporary change in the intercept

Bold and underlined represents relatively stable changes in the intercept

*Item labels represent the Early Adolescent item labels. See Appendix A for corresponding labels in the middle/late adolescent forms 
Table 7

Latent Means and Variances for Strong Invariance PYD-VSF Models

Latent Means

\begin{tabular}{lcrrrrrrr} 
Grade & 5 & 6 & 7 & 8 & \multicolumn{1}{c}{9} & \multicolumn{1}{c}{10} & 11 & 12 \\
\hline Competence & 0.000 & 0.000 & 0.000 & 0.181 & 0.293 & -0.280 & -0.417 & -0.417 \\
Confidence & 0.000 & -0.288 & -0.288 & -0.150 & 0.000 & -0.448 & -0.448 & -0.448 \\
Character & 0.000 & -0.257 & 0.000 & 0.000 & 0.000 & 0.000 & 0.000 & 0.000 \\
Caring & 0.000 & 0.000 & 0.174 & 0.174 & 0.174 & 0.174 & 0.174 & 0.174 \\
Connection & 0.000 & -0.392 & -0.737 & -0.737 & -0.737 & -0.737 & -0.862 & -0.862 \\
PYD & 0.000 & 0.214 & 0.000 & -0.168 & 0.000 & 0.000 & 0.246 & 0.246 \\
& & & & & & & & \\
\hline
\end{tabular}

Latent Variances

\begin{tabular}{lcccccccc} 
Grade & 5 & 6 & 7 & 8 & 9 & 10 & 11 & 12 \\
\hline Competence & 1.000 & 1.000 & 1.000 & 1.000 & 0.763 & 0.763 & 0.763 & 0.763 \\
Confidence & 1.000 & 1.000 & 1.000 & 1.701 & 1.679 & 1.375 & 1.375 & 1.375 \\
Character & 1.000 & 1.000 & 0.574 & 0.574 & 0.430 & 0.430 & 0.430 & 0.430 \\
Caring & 1.000 & 1.000 & 0.751 & 0.751 & 0.846 & 0.846 & 0.608 & 0.608 \\
Connection & 1.000 & 1.000 & 0.743 & 1.000 & 1.000 & 0.748 & 0.748 & 0.748 \\
PYD & 1.000 & 1.000 & 1.277 & 1.444 & 1.277 & 1.277 & 0.998 & 0.998 \\
& & & & & & & & \\
\hline
\end{tabular}

Estimates from analyses where target grade is earliest (e.g., Grade 7 comes from the model of Grades 7, 8, and 9) 
Table 8

Stability and Latent Correlations among the PYD Constructs

\begin{tabular}{|c|c|c|c|c|c|c|c|c|}
\hline Grade & 5 & 6 & 7 & 8 & 9 & 10 & 11 & 12 \\
\hline \multicolumn{9}{|l|}{ Competence with } \\
\hline Competence (at T-1) & na & $0.44^{* * *}$ & $0.47^{* * *}$ & $0.53^{* * *}$ & $0.76^{* * *}$ & $0.83^{* * *}$ & $0.66^{* * *}$ & $0.83^{* * *}$ \\
\hline Confidence & $1.00^{\dagger}$ & $0.80^{* * *}$ & $0.76^{* * *}$ & $0.78^{* * *}$ & $1.00^{* * *}$ & $0.83^{* * *}$ & $0.92^{* * *}$ & $0.75^{* * *}$ \\
\hline Character & $0.25^{* * *}$ & $0.17^{* *}$ & 0.06 & 0.06 & $0.24^{* * *}$ & 0.02 & $0.24^{* *}$ & $0.25^{* *}$ \\
\hline Caring & na & -0.01 & -0.06 & 0.01 & -0.04 & $-0.13^{*}$ & -0.12 & 0.10 \\
\hline Connection & $0.42^{* * *}$ & $0.46^{* * *}$ & $0.40^{* * *}$ & $0.33^{* * *}$ & $0.56^{* * *}$ & $0.66^{* * *}$ & $0.63^{* * *}$ & $0.55^{* * *}$ \\
\hline \multicolumn{9}{|l|}{ Confidence with } \\
\hline Confidence (at T-1) & na & $0.39^{* * *}$ & $0.66^{* * *}$ & $0.43^{* * *}$ & $0.83^{* * *}$ & $0.87^{* * *}$ & $0.70^{* * *}$ & $0.70^{* * *}$ \\
\hline Character & $0.25^{* * *}$ & $0.17^{*}$ & $-0.15^{*}$ & -0.06 & $0.12^{* * *}$ & $-0.16^{* *}$ & -0.01 & -0.04 \\
\hline Caring & na & -0.06 & $-0.24^{* * *}$ & $-0.19^{* * *}$ & $-0.12^{*}$ & $-0.20^{* * *}$ & $-0.19^{* *}$ & $-0.14^{*}$ \\
\hline Connection & $0.42^{* * *}$ & $0.39^{* * *}$ & $0.17^{*}$ & $0.32^{* * *}$ & $0.34^{* * *}$ & $0.43^{* * *}$ & $0.42^{* * *}$ & $0.52^{* * *}$ \\
\hline \multicolumn{9}{|l|}{ Character with } \\
\hline Character (at T-1) & na & $0.25^{* *}$ & $0.43^{* * *}$ & $0.62^{* * *}$ & $0.64^{* * *}$ & $0.69^{* * *}$ & $0.79^{* * *}$ & $0.62^{* * *}$ \\
\hline Caring & na & $0.56^{* * *}$ & $0.44^{* * *}$ & $0.48^{* * *}$ & $0.50^{* * *}$ & $0.51^{* * *}$ & $0.55^{* * *}$ & $0.52^{* * *}$ \\
\hline Connection & $0.30^{* * *}$ & $0.54^{* * *}$ & $0.35^{* * *}$ & $0.41^{* * *}$ & $0.42^{* * *}$ & 0.10 & $0.18^{*}$ & 0.16 \\
\hline \multicolumn{9}{|l|}{ Caring with } \\
\hline Caring (at T-1) & na & na & $0.31^{* * *}$ & $0.50^{* * *}$ & $0.53^{* * *}$ & $0.38^{* * *}$ & $0.51^{* * *}$ & $0.49^{* * *}$ \\
\hline Connection & na & $0.18^{* *}$ & $0.24^{* * *}$ & $0.20^{* * *}$ & $0.14^{*}$ & 0.10 & -0.06 & -0.06 \\
\hline \multicolumn{9}{|l|}{ Connection with } \\
\hline Connection (at T-1) & na & $0.59^{* * *}$ & $0.78^{* * *}$ & $0.64^{* * *}$ & $0.78^{* * *}$ & $0.62^{* * *}$ & $0.72^{* * *}$ & $0.93^{* * *}$ \\
\hline \multicolumn{9}{|l|}{ PYD } \\
\hline PYD (at T-1) & na & $0.81^{* * *}$ & $0.70^{* * *}$ & $0.78^{* * *}$ & $0.81^{* * *}$ & $0.90^{* * *}$ & $0.82^{* * *}$ & $0.81^{* * *}$ \\
\hline
\end{tabular}

$* p<.05 * * p<.01 * * * p<.001{ }^{\dagger}$ fixed parameter

Estimates from analyses where target grade is earliest (e.g., Grade 7 comes from the model of Grades 7,8, and 9) 
Table 9

PYD-VSF Correlations with Criterion Variables

\begin{tabular}{|c|c|c|c|c|c|c|c|c|}
\hline Grade & 5 & 6 & 7 & 8 & 9 & 10 & 11 & 12 \\
\hline $\begin{array}{l}\text { PYD with } \\
\text { Contribution } \\
\text { Depression } \\
\text { Risk }\end{array}$ & $\begin{array}{l}0.21^{* * *} \\
-0.68^{* * *} \\
-0.46^{* * *}\end{array}$ & $\begin{array}{r}0.41^{* * *} \\
-0.55^{* * *} \\
-0.52^{* * *}\end{array}$ & $\begin{array}{l}0.41^{* * *} \\
-0.52^{* * *} \\
-0.50^{* * *}\end{array}$ & $\begin{array}{l}0.44^{* * *} \\
-0.52^{* * *} \\
-0.54^{* * *}\end{array}$ & $\begin{array}{r}0.53^{* * *} \\
-0.49^{* * *} \\
-0.60^{* * *}\end{array}$ & $\begin{array}{l}0.58^{* * *} \\
-0.40^{* * *} \\
-0.61^{* * *}\end{array}$ & $\begin{array}{r}0.56^{* * *} \\
-0.47^{* * *} \\
-0.57^{* * *}\end{array}$ & $\begin{array}{r}0.57^{* * *} \\
-0.47^{* * *} \\
-0.66^{* * *}\end{array}$ \\
\hline $\begin{array}{l}\text { Competence with } \\
\text { Contribution } \\
\text { Depression } \\
\text { Risk }\end{array}$ & $\begin{array}{c}0.19^{* * *} \\
-0.18^{* * *} \\
0.03\end{array}$ & $\begin{array}{l}0.27^{* * *} \\
-0.23^{* * *} \\
0.12^{* *}\end{array}$ & $\begin{array}{l}0.20^{* * *} \\
-0.21^{* * *} \\
0.09^{*}\end{array}$ & $\begin{array}{c}0.20^{* * *} \\
-0.26^{* * *} \\
0.15^{* *}\end{array}$ & $\begin{array}{l}0.25^{* * *} \\
-0.42^{* * *} \\
0.10\end{array}$ & $\begin{array}{l}0.15^{* * *} \\
-0.38^{* * *} \\
0.02\end{array}$ & $\begin{array}{l}0.21^{* * *} \\
-0.40^{* * *} \\
0.08\end{array}$ & $\begin{array}{l}0.27^{* * *} \\
-0.41^{* * *} \\
0.09\end{array}$ \\
\hline $\begin{array}{l}\text { Confidence with } \\
\text { Contribution } \\
\text { Depression } \\
\text { Risk }\end{array}$ & $\begin{array}{c}0.19^{* * *} \\
-0.18^{* * *} \\
0.03\end{array}$ & $\begin{array}{c}0.17^{* *} \\
-0.28^{* * *} \\
0.15^{* *}\end{array}$ & $\begin{array}{l}-0.01 \\
-0.34^{* * *} \\
0.13^{* *}\end{array}$ & $\begin{array}{r}0.01 \\
-0.38^{* * *} \\
0.25^{* * *}\end{array}$ & $\begin{array}{r}0.06 \\
-0.44^{* * *} \\
0.21^{* * *}\end{array}$ & $\begin{array}{l}-0.05 \\
-0.46^{* * *} \\
0.13^{* * *}\end{array}$ & $\begin{array}{l}-0.02 \\
-0.43^{* * *} \\
0.12^{* *}\end{array}$ & $\begin{array}{r}0.06 \\
-0.52^{* * *} \\
0.17^{* * *}\end{array}$ \\
\hline $\begin{array}{l}\text { Character with } \\
\text { Contribution } \\
\text { Depression } \\
\text { Risk }\end{array}$ & $\begin{array}{l}0.33^{* * *} \\
0.11^{*} \\
-0.03\end{array}$ & $\begin{array}{l}0.39^{* * *} \\
0.09^{*} \\
0.02\end{array}$ & $\begin{array}{l}0.47^{* * *} \\
0.23^{* * *} \\
-0.05\end{array}$ & $\begin{array}{l}0.49^{* * *} \\
0.22^{* * *} \\
-0.01\end{array}$ & $\begin{array}{l}0.36^{* * *} \\
0.22^{* * *} \\
0.00\end{array}$ & $\begin{array}{l}0.38^{* * *} \\
0.31^{* * *} \\
0.12^{* *}\end{array}$ & $\begin{array}{l}0.31^{* * *} \\
0.21^{* * *} \\
0.07\end{array}$ & $\begin{array}{l}0.34^{* * *} \\
0.24^{* * *} \\
0.26^{* * *}\end{array}$ \\
\hline $\begin{array}{l}\text { Caring with } \\
\text { Contribution } \\
\text { Depression } \\
\text { Risk }\end{array}$ & $\begin{array}{l}\text { na } \\
\text { na } \\
\text { na }\end{array}$ & $\begin{array}{l}0.18^{* * *} \\
0.09^{*} \\
-0.03\end{array}$ & $\begin{array}{l}0.32^{* * *} \\
0.24^{* * *} \\
0.04\end{array}$ & $\begin{array}{l}0.30^{* * *} \\
0.26^{* * *} \\
0.03\end{array}$ & $\begin{array}{l}0.15^{* * *} \\
0.21^{* * *} \\
0.08\end{array}$ & $\begin{array}{l}0.15^{* * *} \\
0.20^{* * *} \\
0.06^{*}\end{array}$ & $\begin{array}{l}0.17^{* * *} \\
0.28^{* * *} \\
0.05\end{array}$ & $\begin{array}{l}0.15^{* *} \\
0.13^{* *} \\
0.14^{* *}\end{array}$ \\
\hline $\begin{array}{l}\text { Connection with } \\
\text { Contribution } \\
\text { Depression } \\
\text { Risk }\end{array}$ & $\begin{array}{l}0.35^{* * *} \\
0.01 \\
0.03\end{array}$ & $\begin{array}{l}0.37^{* * *} \\
-0.11 \\
0.06\end{array}$ & $\begin{array}{l}0.50^{* * *} \\
-0.06 \\
0.07\end{array}$ & $\begin{array}{l}0.44^{* * *} \\
-0.05 \\
0.01\end{array}$ & $\begin{array}{l}0.38^{* * *} \\
-0.16^{* *} \\
-0.03\end{array}$ & $\begin{array}{l}0.24^{* * *} \\
-0.35^{* * *} \\
0.00\end{array}$ & $\begin{array}{l}0.29^{* * * *} \\
-0.38^{* * *} \\
0.12^{*}\end{array}$ & $\begin{array}{l}0.29^{* * *} \\
-0.40^{* * *} \\
0.16^{*}\end{array}$ \\
\hline $\begin{array}{l}\text { Contribution with } \\
\text { Depression } \\
\text { Risk }\end{array}$ & $\begin{array}{l}-0.09^{* *} \\
-0.08^{*}\end{array}$ & $\begin{array}{l}-0.19^{* * *} \\
-0.17^{* * *}\end{array}$ & $\begin{array}{l}-0.11^{* * * *} \\
-0.19^{* * *}\end{array}$ & $\begin{array}{l}-0.14^{* * * *} \\
-0.21^{* * *}\end{array}$ & $\begin{array}{l}-0.16^{* * *} \\
-0.27^{* * *}\end{array}$ & $\begin{array}{l}-0.14^{* * *} \\
-0.27^{* * *}\end{array}$ & $\begin{array}{l}-0.16^{* * *} \\
-0.25^{* * *}\end{array}$ & $\begin{array}{l}-0.22^{* * *} \\
-0.22^{* * *}\end{array}$ \\
\hline $\begin{array}{l}\text { Depression with } \\
\text { Risk }\end{array}$ & $0.25^{* * *}$ & $0.29^{* * *}$ & $0.27^{* * *}$ & $0.20^{* * * *}$ & $0.23^{* * *}$ & $0.27^{* * *}$ & $0.12^{* * *}$ & $0.23^{* * *}$ \\
\hline
\end{tabular}

Estimates from analyses where target grade is earliest (e.g., Grade 7 comes from the model of Grades 7, 8, and 9) 


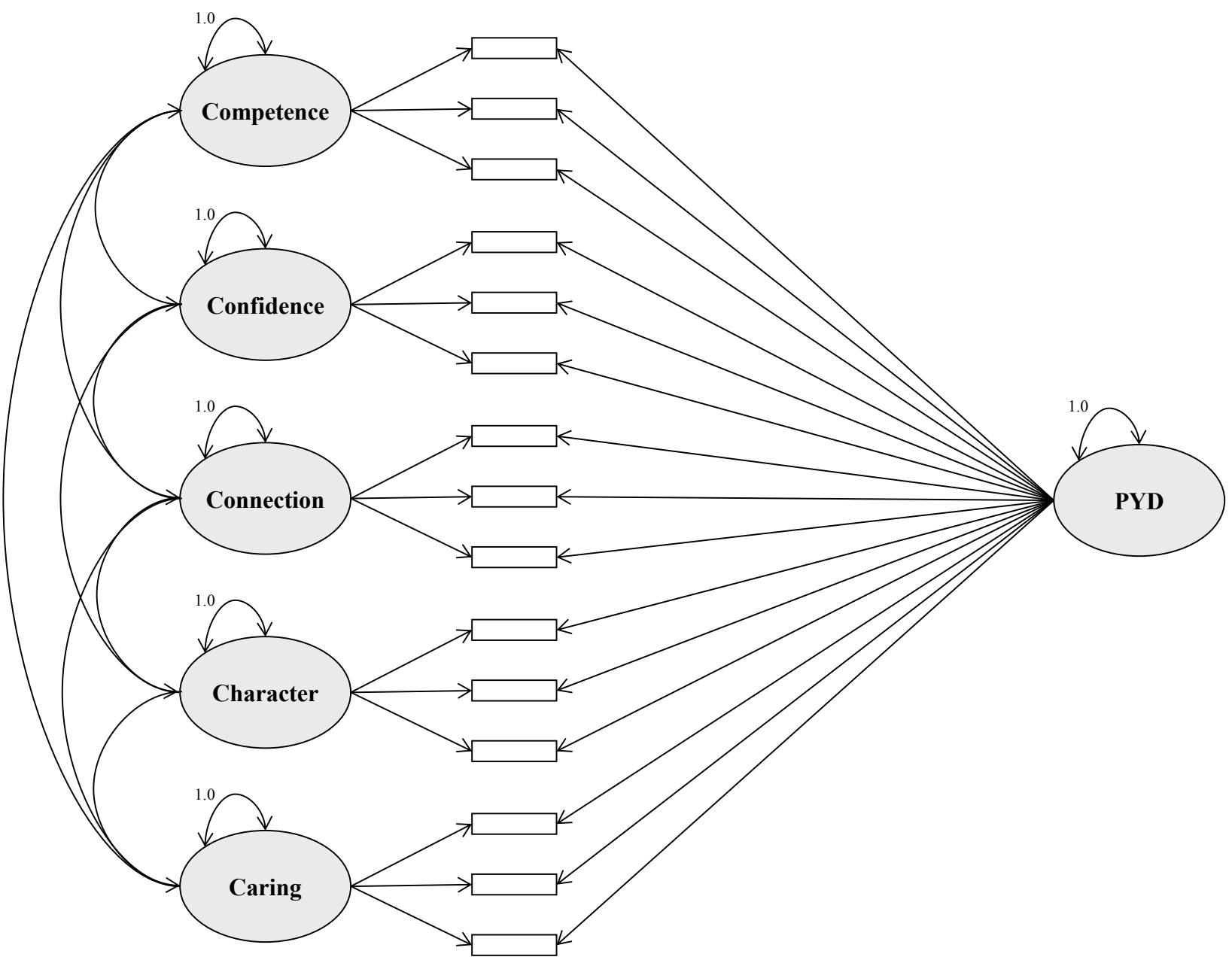

Figure 1. A hypothetical bifactor model of PYD 